\title{
Gamification and the Quality of Informal Post-Experiential Learning
}

\author{
VIKTORIA LAMBERT \\ Budapest University of Technology and Economics, Hungary \\ victoria@lambert-mail.com
}

\begin{abstract}
As corporate learning moves out of the classroom into the hands of learners, the responsibilities of those who provide guidance in this process are changing. The overall prevalence of learning tools creates a need for competent learning leaders who make decisions about the development of the workforce. With special focus on the least used gamified learning tool, the aim of the study was to investigate the enablement of gamified learning tools determined by certain attributes of this research. A questionnaire survey had been conducted on a selected sample of 100 high-level learning leaders from 28 countries to examine if there are significant correlations between the usage of gamified learning tools and corporate learning leaders' minds, their competences and the organizational culture profiles of companies. Results had been analysed with the sPss statistical software package and indicated that relationships between these variables cannot be categorically proven, so no predictions can be made about the future of gamified learning based on these attributes. It is the highest time to conduct an extensive research to examine relationships between the quality of informal learning and learning tools in the гст domain.
\end{abstract}

Key words: learning leader, CLO, informal learning, learning tools, gamified learning https://doi.org/10.26493/1854-4231.12.249-271

\section{Introduction}

The usage of information and communication technologies (Iст) gained its stable and indispensable place in the fast moving reality of many companies, having positive impacts on economic growth, productivity and efficiency. As learning moves out of the classroom into the Іст labyrinth and in the hands of learners, the responsibilities of those who give guidance about how we should behave in this labyrinth are changing. The new tools of social communication have brought an era where we have to rethink learning, knowledge sharing and collaboration in a fundamentally different way than ever before. The newest achievements of information technology 
do not let us sustain concentration longer (Carr 2010), the information overload is urging us to continually browse and scan contents. Rapid movements of markets and constant rollouts of new strategies require quick, easy access to learning so there is a need to develop competent leaders and employees who can adapt to this pace of change. Not as quick and easy as it may sound, new strategies must first be implemented and this requires transformational learning (Floyd and Lane 200o). New strategy implementation often includes the complexity of changing the organization structure, culture, competencies, and leadership styles. The rigid curriculum and formal learning are replaced by cross-functional content that can satisfy curiosity and thus, informal learning can occur. This new type of learning is more and more loosely-structured, adapting itself in time, space and in tools to the 'here and now' needs of learners. As technology becomes an increasingly important part of learning, the modern learning leader is tasked with sourcing and leveraging new learning tools, including gamified learning that has been rapidly gaining ground as a tool of practicing managers, specialized consultants and providing promising research area of management and organization scholars. Therefore, the aim of this paper is to investigate the learning leader and the organizational culture profile of the company as mediums for the usage of a selected learning tool: gamified learning.

The purpose of this paper is to explore if there are significant correlations between the usage of gamified learning tools and corporate learning leaders' minds, their competences and the perceived organizational culture profiles of their companies.

Survey data collected from a selected sample of learning leaders has been used to examine possible impact. These learning leaders are the Chief Officer, Head, SVP, vP, Director or Expert of Learning, Learning and Development, Training and Development, etc., all referred to as learning leader or Chief Learning Officer (cLo) throughout this research while acknowledging the diversity of job titles and responsibilities. In the course of the primary research, eight cLos provided their feedback throughout a test-surveying phase, and seven expert opinions had been integrated in my main research survey. Seeking a global analysis, I managed to gather survey respondents from 28 different countries. The selection of sectors and organizations with more developed corporate learning practices had been initiated by the fifth edition of the Corporate Universities \& Corporate Le@rning Summit Series, the one of its kind conference of corporate learning professionals with the highest attendance in 
Europe. The target audience of this event series was especially responsive and interested in the research focus and the development of the cLo's role, so I finally received 100 completed surveys. Several surveys, however, were not taken into consideration due to missing data, so the final sample consisted of 82 learning leaders.

The contribution of the paper is that it extends previous research findings about gamified learning while testing the correlations between this learning tool's usage and unique characteristics as corporate learning leaders' minds, their competences and the organizational culture profiles of their companies. Amongst learning tools currently in use, gamified learning is the least used and we still do not know if it is a fad or learning leaders will facilitate its predominance. In this research, relationships between these variables cannot be categorically proven so based on these no predictions can be made about the longevity of gamified learning. Therefore, this exploratory paper investigates gamified learning from the practical side, based on a semi-structured interview conducted with a gamification expert.

The paper consists five parts. After the introduction, the theoretical background had been examined and research propositions had been developed. Next, the research methodology is presented, including sample description and research instrument, data analysis results and main research findings. After conducting an extended survey with a unique sample of learning leaders and analysing the results, I could not found statistically significant relationships between the variables of learning leader minds, their competences, the organizational culture profile and the usage of gamified learning, so the real drivers of its implementation need to be found elsewhere. This study suggests that there is much to be learned from gamifiers themselves who are responsible for the elements, mechanics and design of their gamified learning implementations, so I conducted an in-person interview with a game design expert. The interview was guided by the scope of this research and main research findings are provided in the fourth part. Finally, research results are discussed from both theoretical and practical standpoint, research limitations are outlined, and directions of future research are suggested.

\section{Informal Post-Experiential Learning Enabled by IC T Tools and Qualities of Learning Leaders}

In a previous study about informal post-experiential learning, we were investigating in which forms emerging learning tools can occur and how they are situated within the learning ecosystem, as well 
as what kind validation mechanisms are effective based on the possible use in practice. Drawing on our theoretical and empirical research, prior expert advisor feedbacks, and the content analysis of presentations delivered at the aforementioned Corporate Universities \& Corporate Le@rning Summit Series, we attempted to develop a framework for the emerging tools in corporate learning ecosystems. This alternative framework of emerging learning tools in the postexperiential informal learning process described social learning as the engine of Communities of Practice (CoPs), and gamified tools as amplifiers of the learning ecosystem (Szeghegyi, Szoboszlai, and Velencei 2014).

In post-experiential learning, the emphasis needs to be put also on how to become competent in the application of tools. According to Polányi's original idea published in the frequently cited book Personal Knowledge (Polányi 1962), competence implies the ability of expertise within a certain domain and the ability to not only submit to the rules but also by reflection influence the rules of the domain or the tradition. Competence is thus not a property but a relation between individual actors and a social system of rules. It is remarkable how much even kids can learn and with how little guidance if their self-motivation, self-discipline and self-organization are encouraged and enabled.

Efficient and independent learning means that one is able to learn persistently, to plan his own learning path - individually and in groups as well - and that includes effective time management and information management. It is essential to continuously explore possibilities for improving competencies with regard to digitalization as well. Digital innovation is of vital importance in course dynamic, course layout and curriculum development. It is necessary to identify areas in which digital innovation can influence the development of subject specific competences: information systems competences, project work competences, business competences and specialized Iст field competences. In the battle against formal learning that many of the students increasingly find dull, there is a need for informal as well where the learning content and the knowledge as such learn 'on the go.' This is a knowledge refresher process whilst not the subject, but the people are becoming more educated. In this process, the passionate learner can increase his knowledge, frame up new contents, develop and strengthen their self-efficacy by mastery experiences and by modelling observational learning, verbal persuasion and judgments of their own physiological states (Wood et al. 1989). In corporate learning environments, an emerging role 
has been rapidly gaining attention as the primary facilitator and enabler of this process.

When elevating learning leaders to a C-level title (as in the mid1990s Jack Welch gave Steve Kerr first the title of the Chief Learning Officer (CLO) at General Electric), the question arised: does that mean that a completely new profession had been created? The review of the literature resulted in a broad set of dimensions that represented various characteristics, overlaps with roles of other $\mathrm{CxOs}$ and far too large potentially uncovered areas. Interviews conducted with ten high-level American cLos collected information straight from the source and identified five questions of interest: where today's clos come from and how do they fit in the organizational chart with reporting relationships and salaries; cEo's charge to the CLO; the CLO mission; CLO priorities and key initiatives; and CLo performance measures. Based on the responses of the most credible source of information, the only path of cLo survival is to be strategic and focus on Stage1: Employee Development, Stage2: Imminent Business Needs, Stage3: Unknown Business Development (model of Learning Strategy Evolution). Based on further results of the study, the idealized cLo profile has the following key elements: a high comfort level with senior managers and boards, a record of success running an organizational unit as well as literacy with learning processes and technologies. The two critical points of variance in CLO profiles are: (1) whether the person put in the cLo role is a company 'insider' or someone brought in from the outside (maybe from academia or a consulting firm), and (2) whether the person's background and experience is in the educational arena or he/she is an operating line manager (Baldwin and Danielson 2000). Today's cLos have to implement new technologies, partnerships and business strategies to transform the way their organizations transfer knowledge and skills to employees. That includes establishing strategic alignments with business leaders across the organization, delivering development opportunities via social, mobile and other platforms so that employees feel empowered to get the information and education they need. There had been various research attempts to investigate critical attributes of cLOs, including current and future trends related to the position and the competencies important to cLo success (L'Allier 2005) or CLo's critical characteristics for success where talent management, succession planning and organizational development experience could be found on the top of the list (Buongiorno et al. 2005). The role and the responsibilities of the most senior learning leader have broadened since 2005, when ASTD and

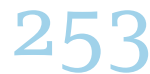


the University of Pennsylvania collaborated on a survey to find out more on the learning leader population and the new breed of learning executive. Focusing on a selected sample of 92 mostly us-based CLOS, the article profiled the positions, career histories and educational backgrounds and reported on the competences these heads of learning believed to be critical for success. One of the greatest challenges that emerged was quantifying the value of learning at work. These earlier (and with the fast pace of change in a way obsolete) survey findings show about the organization's most senior learning executives that they are busy with aligning learning requirements with business goals and providing learning opportunities in the most efficient manner, while aiming to develop their key competences of leadership and the ability to articulate the value of learning in business terms (Sugrue 2006). We are moving beyond commoditized learning curating knowledge that is unique to how a given company makes money and drives growth. In the learning enterprise (Gratton 2014) CLOS' responsibilities expand, they are often working directly with CEOS and become from Service Providers not merely Strategic Business Partners, but Value Creators (Gratton 2004; Elkeles and Phillips 2007). According to Rob Lauber, acting cLO at McDonald's Corp., who has held cLo roles in major global organizations for the past 15 years, and experienced transformations first-hand, the role has shifted over the years, from Leader of a Training Portfolio to Enabler of Learning. The cLo has to give up control of the learning process, and focus more on creating opportunities for learners to get the information they need when they need it, even if that means shutting the door on classrooms (Gale 2015). Additional theoretical background for the learning leader competencies of this study had been provided by the University of Pennsylvania's Executive Doctoral Program, pennclo (see www.gse.upenn.edu), the one of its kind among top-tier universities, integrating academics with the realities of the workplace. This establishment is considered as a key component to cultivating future clos. Besides the pennclo Course Blocks, the ASTD Competency Study: Training and Development Redefined (Arneson et al. 2013) had been investigated. This latest contribution to the ASTD Competency Model legacy offered a broad inventory of topics that cLos need to recognize to be successful in the rapidly changing business environment, as well as key specific actions these professionals must take to succeed.

With the development of science and technology complementing each other, it is observed that education has emerged from a conservative, isolative and traditional structure and it has gained a new

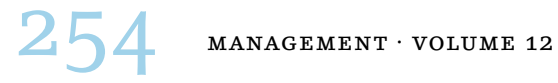


identity. Worldwide educational structures and processes are rapidly affected by each other (James et al. 2010) and require leaders with a global mind-set of the future, thinking globally but acting locally and nationally, furthermore, to be individuals with enhanced creativity skills, respect for themselves as well as for others, and global ethical values who can make personal and professional synthesis in one or more disciplines (Gardner 2007). Gardner (2008) conducted mind oriented research in his several books and publications and called his theoretical approach 'Five Minds of the Future.' This taxonomy entails the disciplined mind (to learn at least one profession, as well as the major thinking behind it), the synthesizing mind (to organize the massive amounts of information and communicate effectively to others), the creative mind (to revel in unasked questions - and uncover new phenomena and insightful answers), the respectful mind (to appreciate the differences between human beings and understand and work with all persons) and the ethical mind (to fulfil one's responsibilities as both a worker and a citizen).

Advancements in science and technology are becoming radical game changers to this approach, altering strategies that allow people to maintain moral and ethical standards, do 'good work' (Gardner, Csikszentmihalyi, and Damon 2001). Consequently, concepts such as worldwide teacher competency standards, interdisciplinary curricula, knowledge economy, sharp minds (Farr 2014) are evolving, preparing the emergence of new mind interpretations i.e. a conceptual model for affective development had been examined and applied to the use of games and simulations. Games are identified as offering the optimum environment for development of the ethical mind as they offer the opportunity to explore ethical problems and see the consequences and experience the emotional impact of the solutions (Smith 2008).

The formal, traditional methods are no longer sufficient to remain competitive in the knowledge economy, and organizational cultures, thus corporate learning environments play a vital role in this transformation process. Schein formally defined culture as 'a pattern of shared basic assumptions learned by a group as it solves its problems of external adaptation and internal integration, which has worked well enough to be considered valid and, therefore, to be taught to new members as the correct way to perceive, think, and feel in relation to those problems' (Schein 1996). Organizational culture is comprised of three different levels at which the cultural phenomenon is visible to the observer (Schein 2010). The three levels of culture are (1) artefacts, (2) espoused beliefs and values, and (3) basic underly- 
ing assumptions. Understanding the learning process by which basic underlying assumptions evolve is critical to a better understanding of an organization's culture (Schein 2010). The exploration of the relationship between organizational culture values and individual personality types had been conducted by O'Reilly and the Organizational Culture Profile (ОсP) instrument was created to assess a person's fit with a particular culture or industry ( $\mathrm{O}^{\prime}$ Reilly, Chatman, and Caldwell 1991). The authors suggested that employees who were not a good fit with an organization, because of either job tasks or organizational culture, were likely to quit because of reduced job satisfaction and commitment to the organization as compared to employees who were a good fit. In their study of 224 graduate students in the мвA program, they reported an average reliability coefficient of 0.73 for the instrument. Two other studies confirmed the reliability of the instrument. First, Chatman reported a reliability coefficient of 0.88 for 171 entry-level auditors in eight us public accounting firms (Chatman 1991). Second, Vandenberghe reported a reliability coefficient of 0.86 for 565 individuals belonging to 19 hospitals in healthcare organizations (Vandenberghe 1999). However, the ocp lacks elements commonly found in other industries such as hospitality (Enz 1988; Woods 1989).

The most influential scholars of organizational culture (Cameron and Ettington, 1988; O'Reilly and Chatman 1996; Schein 1996) have adopted a sociological perspective regarding how members within an organization viewed values, underlying assumptions, and expectations and how they interpreted the surrounding environment. The ocP provided a framework that has a high degree of congruence with the sociological perspective of organizational culture and thus, was used in this study as an additional possible influencer of the learning tools in use.

This research is designed to explore whether the selected attributes play a critical role in determining the usage of the selected gamified learning tool, therefore the theoretical background of gamification and relevant findings about gamified learning as a postexperiential learning tool had been reviewed as well.

Gamification has been broadly defined as using game mechanics in non-game contexts to impact motivation (Deterding et al. 2011; Kapp 2012; Nicholson 2012). For this study, the aspect of learning was added to the definition. In other words, gamification is about motivating individuals to participate in a learning event through the addition of game elements, not full-fledged games (Nicholson 2012). Games can potentially present learning opportunities using strate-

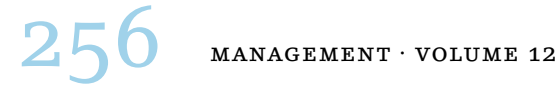


gies that allow contextualized learning. Games offer a means of applying and practicing skills by presenting content in a manner that makes sense to the environment (Van Eck 2006). This type of learning becomes meaningful and beneficial to the learner, unlike inert knowledge gained through decontextualized methods like classroom worksheets (Rieber 1996). Extracting design elements from games and embedding them into learning environments as a means of gamifying instruction has potential for increasing learner motivation and student learning (Van Eck 2007). Using goals, rules, interaction, time, reward, feedback, challenge, storytelling, curves of interest, aesthetics, and the ability to fail with minimal consequence can result in learning environments where there is increased motivation, retention and application of learning (Garris, Ahlers, and Driskell, 2002; Kapp 2012). However, the goal of gamification is to improve instruction, not replace it, so if content is not already effective then adding gamification will yield little result (Landers 2014). Gamification is about using game attributes to draw individuals into the fun, leaving them excited about experiencing learning (Arnold 2014) and it is used to enhance learning programs (Dale 2014; Uskov and Sekar 2014), make tutorials more engaging (Deterding 2012; Li, Grossman, and Fitzmaurice 2012; Rauch 2013) and can be an extra layer of properly developed knowledge management while initiating, sustaining and supporting desired behaviours and adherence to values (Shapkova, Dorfler, and MacBryde 2017). However, organizations are still sceptical about gamification as a means to engage and motivate target audiences and they struggle to understand the trend and its longer-term implications (Burke 2012). It is an increasingly popular approach, which has been shown to be powerful in many areas so the question arises what are the key drivers of its viability and longevity in corporate learning environments.

Today we are starting to see the fuzzy outlines of an emerging corporate role that will make a significant impact not only on the informal post-experiential corporate learning processes but also on the age-old notion of life-long learning, largely depending on the critical factors in application of learning tools. In this research process, I attempt to investigate the learning tool usage with special focus on gamified learning. The research had been conducted on a selected sample of high-level corporate learning leaders. Consequently, the following research propositions were declared:

RP1 There is a significant relationship between the extent of gamified learning usage and corporate learning leaders' minds. 
RP2 There is a significant relationship between the extent of gamified learning usage and corporate learning leaders' competences.

RP3 There is a significant relationship between the extent of gamified learning usage and the organizational culture profiles of the learning leaders' companies.

RESEARCH METHODOLOGY

This study is focused on post-experiential education, where corporate learning leaders are the guides of a journey from 'knowledge' to 'knowing,' and bridging the gap between the 'know how' (concepts brought from the university) and 'know when' (on-the-job context in a corporation) (Szoboszlai, Velencei, and Baracskai 2014). To be successful in the learning enterprise, today's clos need to become technology champions, support user-generated content, advanced search tools, community-based learning, mobile learning, video learning, learning record storage and curation. Most of these technologies need to be mainstreamed with the cLo model and therefore, further research is needed relating to understanding the relationships between cLo attributes and the application of learning tools within the organization.

To investigate the leader who is responsible for the professional education of the workforce, a quantitative survey approach was selected. Based on previous research, the literature review and semistructured interviews with learning leaders, survey questions have been formulated. To support the content and structure of the survey instrument, pre-pilot expert validation was conducted. The questions were targeted for learning leaders including chief learning officers, training directors, and other learning leader types of various industries as this study wanted to examine who is behind the organizational learning initiatives and can have an impact. The overall purpose of the survey was to investigate perceptions and characteristics of certain learning leader profiles, and link this to the impact of the corporate learning programs they lead.

The research sample was very carefully selected. It comprised of senior-level individuals from the corporate university or corporate learning department of the organization. The survey had been conducted in August 2015 and it had been fully completed by 82 learning leaders $(65,2 \%$ male; $34,8 \%$ female) from various industries and 28 different countries. As per the sample characteristics, I emphasized that only the learning function's senior leader can be the respondent, and I set the limit of a minimum of 100 employees in the

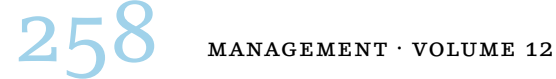


learning population and a minimum of 5 years of corporate learning experience for at least $80 \%$ of the respondent learning leaders. The study required one individual respondent per organization. The sampling procedure started at the annual Corporate Universities \& Corporate Le@rning Summit Series 2015 and subsequently, the webbased questionnaire was conducted using an easy to access internet tool.

The research instrument consisted of a questionnaire survey and as a start, validity analysis was conducted to check the validity of the research instrument. Content validity was attained by adapting items from the literature and previous research. In order to assess whether to expect an acceptable level of understanding, pre-pilot expert validation and test surveying had been conducted among a group of eight learning professionals representing a 'typical' survey respondent from various domains. The learning professionals held titles such as Chief Learning Officer, Director of Learning, Head of Learning and Development, Vice President of Training, Head of Corporate University. Further refinements were made because of the feedback. The full survey included seven sets of questions, with special emphasis on those areas related to main research propositions of this study, and further dominant areas of my research activities. The creation of the survey had been guided by the methodology described in Paul A. Scipione's book, titled Practical Marketing Research (Scipione 1992). The survey and the subsequent interview had been also extended with further questions that were not closely related to the main research propositions and, due to length constraints, could not be examined in this paper.

In the data collection phase of the research, I provided an online, self-guided survey platform and used the five-level Likert scale items to scale the responses (Likert 1932). The use of Likert-scales showed the degree to which there is agreement or disagreement with statements to reflect clear positions on an issue and represent a desirable goal, a transition from ordinal scales to interval scales (Torgerson 1967). The verbal interpretation of the scale used in the questionnaire is given below: $1=$ Not at All, $2=$ Very Little, $3=$ Somewhat, 4 = Quite a Bit, 5 = A Great Deal.

Given the subject of this study, my research activities were triggered by the learning tools in use within the corporate learning environment, focusing on the survey question that asked learning leaders to rate from 1 to 5 on a five point ascending scale these tools according to their extent of current usage within their organizations. The 100 completed questionnaire forms had been exposed to fur-

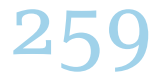


ther inspections to filter them for possible non-sampling errors (data tabulating, coding, etc.) resulting in 82 surveys that could be evaluated. The responses had been coded and analysed in the Statistical Package for Social Sciences (spss v. 19) software. I used descriptive statistics to simplify and present the quantitative descriptions of the data in a manageable form. While evaluating the results, I investigated frequency counts for different variables. To evaluate if there was a statistical evidence for linear relationship, I measured the strength and directions of relationships between variables and the chosen level of statistical significance was $5 \%(p=0.05)$. Following descriptive data analysis, significance (2-tailed) value correlation analysis was conducted to show if there is a statistically significant correlation between the variables.

Prior to narrowing down the scope to the gamified learning tools, my study aimed to explore the extent to which learning leaders are using the previously identified tools within their organization. Based on the responses of learning leaders, their sense making during further validations of the survey question, the notion of learning tools currently in use had been narrowed down to mobile learning, social learning, simulations and gamified learning.

As shown in table 1 by the means (there is no significant difference between the standard deviations), the volume of the social learning tool and simulation users is the highest while gamified learning is the least applied tool within these companies. This is also underlined by the skewness that quantifies how symmetrical the distribution is. The first three graphs have close to symmetrical distribution and therefore a skewness close to zero, while gamification has a higher positive skew (0.512), an asymmetrical distribution with a long tail to the right. The cumulative percentages for 'Not at All' and 'Very Little' responses are also the highest in case of gamified learning.

\section{LEARNING TOOL USAGE IN SURVEYED ORGANIZATIONS}

The survey also investigated Gardner's five minds applied to minds of learning leaders. Initial analysis was conducted to examine the correlation between the applied learning tools and learning leaders' minds. As the results in table 2 show, only the tools of mobile learning, social learning and gamified learning were representing significant correlations at the 0.05 level (2-tailed) with learning leader minds and only with the disciplined mind and the creative mind. The cLOS with dominantly disciplined minds showed the strongest correlations with mobile learning and with gamified learning tools. The clos with dominantly creative minds had the highest correla- 
TABLE 1 Tools Used by Learning Leaders within Their Organization

\begin{tabular}{lrrrr}
\hline Item & $\begin{array}{r}\text { Mobile } \\
\text { learning }\end{array}$ & $\begin{array}{r}\text { Social } \\
\text { learning }\end{array}$ & Simulations & $\begin{array}{r}\text { Gamified } \\
\text { learning }\end{array}$ \\
\hline$N$ & 82 & 82 & 82 & 82 \\
\hline Mean & 2.94 & 3.27 & 3.24 & 2.56 \\
Standard deviation & 1.221 & 1.134 & 1.213 & 1.268 \\
Skewness & 0.035 & -0.029 & -0.017 & 0.512 \\
\hline Not at All* & 14.6 & 4.9 & 7.3 & 23.2 \\
Very Little* & 35.4 & 26.8 & 28.0 & 53.7 \\
\hline
\end{tabular}

Notes * Cumulative percentage.

TABLE 2 Correlations between Learning Leader Minds and Applied Learning Tools

\begin{tabular}{lrr}
\hline Learning tool & $\begin{array}{r}\text { Correlations with } \\
\text { disciplined mind }\end{array}$ & $\begin{array}{r}\text { Correlations with } \\
\text { creative mind }\end{array}$ \\
\hline Mobile Learning & 0.348 & 0.268 \\
Social Learning & 0.120 & 0.365 \\
Gamified Learning & 0.236 & 0.291 \\
\hline
\end{tabular}

tions at the 0.05 level in relationship with social learning, followed by gamified learning and mobile learning respectively. This may indicate the importance of learning leaders' mind in supporting these learning tools. The rest of cLo mind types did not correlate strongly with the learning tools, implying that these variables may not influence the ability of implementing these learning tools by the learning leader.

In the following part of the paper, the scope had been narrowed down to gamified learning exclusively, as this was the tool this study wanted to investigate more.

In the most extensive question of the survey, learning leaders were asked to rate from 1 to 5 on a five point ascending scale these competence attributes according to what extent these describe them and their activities in practice. The research wanted to explore if there are any significant correlations between learning leader competences and the application of gamified learning tools. Based on the results shown in table 3, only the competence attributes below show significant correlations, only at the 0.05 level (2-tailed), and concluded that the extent to which learning leaders apply gamified learning tools within their organizations can not be explained by these competence attributes.

Thus, the RP1 and RP2 cannot be proven, there is no significant relationship between the extent of gamified learning usage and corporate learning leaders' minds or competences. The sample had 
TABLE 3 Learning Leader Competence Correlation with Gamified Learning

\begin{tabular}{lr}
\hline Competence attributes & Correlation \\
\hline Monitoring innovative technologies & 0.327 \\
Curriculum design & 0.323 \\
Establishing and maintaining higher education partnerships & 0.306 \\
Developing performance-based assessments & 0.278 \\
Reviewing all learning modules & 0.270 \\
Managing learning technologies & 0.269 \\
Choosing and blending e-tools from the technology tool box & 0.263 \\
Ensuring security and privacy & 0.254 \\
Leading and managing organizational change & 0.244 \\
Evaluating work-based performance and learning & 0.241 \\
Developing fluency in methodology of measurement and analysis & 0.240 \\
Implications of diversity for work-based learning & 0.226 \\
\hline
\end{tabular}

TABLe 4 Organizational Culture Profile Correlation with Gamified Learning

\begin{tabular}{lr}
\hline Organizational culture profile & Correlation \\
\hline People-oriented & 0.309 \\
Team-oriented & 0.306 \\
Innovative and risk-taking & 0.255 \\
\hline
\end{tabular}

been examined also for statistically significant differences concerning gender as well as age, and no statistically significant differences have been found.

In the course of this investigation, I found important also to examine the company's organizational culture profile (O'Reilly, Chatman, and Caldwell 1991) perceived by cLos - as one of the important influencers of the learning environment they need to manage -, and verify if there are any significant correlations with the application of gamified learning tools. This study wanted to explore if there are any significant relationships between these variables. As shown in table 4 , results revealed that only the organizational culture profiles below show significant correlations, only at the 0.05 level (2-tailed). The extent to which learning leaders use gamified learning tools within their organizations has weak relationships with the dominant organizational culture profile, so the RP3 could not be validated either.

In this study, I presented a research about the usage of different learning tools applied by learning leaders in corporate learning environments with special attention to gamified learning that has been rapidly growing since its recent entrance into the arena of learning tools. After conducting an extended survey with a unique sample of 
learning leaders and analysing the results, I could not found statistically significant relationships between the variables of learning leader minds, learning leader competences, the organizational culture profile and the usage of gamified learning. Therefore, the real drivers of gamified learning tool's implementation need to be found elsewhere. It seemed apparent that there is much to be learned from asking practitioner gamifiers themselves, and collect information from those who are actually responsible for the elements, mechanics and design of their gamified learning implementations.

HOMO LUDENS IN THE CORPORATE LEARNING ENVIRONMENT

The role of the play element of culture and society (Huizinga 1955) is gaining more and more importance in today's corporate learning. After a half century, we call it gamification, which is the application of game-design elements and game principles in non-game contexts (Deterding 2011). It applies behaviour-motivating techniques from traditional and social games to non-game environments. The Human Resources function of any business can leverage gamification techniques to incentivize and reward employees for completing important, but often mundane tasks and the most common ways of doing so are employer branding, recruitment and workforce development.

An award-winning example for the first two HR functions, a game called Multipoly, allows candidates to virtually test their readiness for the job at the firm by working in teams to solve real world business problems. This game presents users with tasks based on the competencies the firm is developing for current employees. The game includes online simulation models, the structure and procedures are specified by the customer (the employer firm) in a 3D environment. Users are following a work routine: going to meetings, accomplishing tasks, and facing unexpected situations and ethical decisions. The system also measures the players based on preset variables (Zielinski 2015) and the results speak for themselves. Candidates who have played the Multipoly game were better prepared for the live face-to-face interviews, as the game pre-educated them about the firm and its vision, services and skills needed for success. Comparing the experience of playing Multipoly with visiting the company's career page, a job candidate might have spent 5-10 minutes on a career page versus spending up to one and half hours playing Multipoly prior to the job interview. Since the game's launch, the employer firm has reported $190 \%$ growth in job candidates with $78 \%$ of users reporting they are interested to learn more about working with them (Meister 2015). Besides its outstanding talent acqui- 
sition results, this solution has given high value for the employer company because it simulated the corporate culture for candidates and introduced the firm in a highly interactive way (Shukla-Pandey 2014).

The developer of Multipoly, Games for Business Ltd. deals with gamification development projects since 2013 (developing different gamified platforms since 2006), supporting recruitment and training processes within the HR activities of large enterprises, focusing primarily on the expectations of employees from younger generations. Besides their employer branding and recruitment profiles, the current research aims to focus more on their platform primarily for the learning leaders and their learner target audience, as described earlier. Based on our basic understanding of the platform, we conducted a semi-structured interview with gamification expert Balázs Vendler, the founder of Games for Business (personal communication, 10 November 2015). The Enterprise Game Platform allows employees to acquire corporate information and improve their knowledge voluntarily, in an entertaining environment. This modular platform includes numerous mini games that transform existing corporate content into fun, motivating learning scenarios, and improve the engagement and commitment of employees. The flexibility of the system allows various new games to be added to the collection at any time and a broad range of benefits to meet different requirements, depending on learning leaders and their learning environments within the organization. Balance between standardization and localization, ease of implementation and customization are provided. Furthermore, efficient players can experience improved learning and absorption, analysers can track activity and measure, learning leaders can optimize costs thanks to reduced classroom hours as well as expenses, and employees 'on the go' can have access to an optimized interface on any device.

In what extent off-the-shelf vs. tailor-made? Our interview revealed that there are different types of client behaviours and needs. The first type of client gets a feel of the game through a demo, is completely satisfied and wants to buy the full version. The second type has a problem to solve, so the process entails ca. $60 \%$ software development and $40 \%$ tailor-made solutions. The third type has a strategic goal, so there is $10 \%$ software development and the emphasis is placed on $90 \%$ alignment to the client's needs. The Multipoly platform included $20 \%$ software development and $80 \%$ iteration to the firm's goals. The involvement of the corporate Iт is typically not influencing the process, apart from basic questions about the server 
environment and the integration into the internal system. According to the founder, the next development goal is to find out what does it take to make the $10 \%$ software part 'self-service' and decrease that $10 \%$ continuously.

The length depends on the goal of the game. Global (and glocal) companies today need employees hired, onboarded and productive as quickly as possible. Further, when the business changes, the skillsets for their existing employees need to adapt even faster. This constant state of transformation is forcing learning leaders to think more strategically about how, when and where training is delivered. Game mechanics are being applied differently to different types of learning goals to drive different types of behaviours. If the goal is onboarding and sharing the most information about the company and its culture, the game's main purpose is to motivate to attract and motivate to play as much as possible. However, if the goal is developing the existing workforce, the game has to prolong the learning process, limit the time employees can spend with the game per day and motivate them to play every day. It should not take too much time per day so daily limits can be set according to the desired learning curve.

How to make more sense of gamified learning's data internally and externally? The agile orientation of the system's data storage design process is important to ensure that the system meets current requirements and presents valuable and actionable outputs. The game's admin system is logging everything and typically, the cumulative results can be seen, however, all different kind of data can be made transparent. If the processes and the points are the same, the system is comparable and universal. In the same platform, any game can be parameterized to different things and broken down to different modules. Various types of games can have matching dashboards thanks to the compatible parameters. The goal is to look beyond the points and qualify data, identify behavioural patterns and recommend new strategies for managing and optimizing the content. As previous research has documented, cloud-computing technology makes a significant impact on input-output data quality dimensions of collaborative processes. This technology strongly increases accessibility, completeness, comprehensiveness, consistency, and decreases limitation of data amount, reliability, and security. In this previous study, external collaboration with universities had to be formalized and enable knowledge transfer relationship. Implementing the cloud computing technology enabled a more efficient and efficient execution of external cooperation and collaboration processes 
(Petkovics et al. 2014) and we can observe the emerging trend that there are more than 50 providers offering cloud-based gamification products, including the biggest players in the gamification arena: Badgeville, BunchBall, and Gamify.

Thus, these additional aspects around ease of integrity, length of play and data usage might indicate that the future implementation of gamified learning tools could be influenced by more platformrelated factors and not learning leader- or learning environmentrelated ones. There is a need to investigate those elements, which have the significant influence on the viability of gamified learning in corporate learning environments.

\section{Conclusion}

The overall objective of this paper is to shed a new light on the viability and longevity of gamification and investigate if gamified learning is a fad, or learning leaders will facilitate its predominance. To accomplish this objective, a questionnaire survey was conducted on a selected sample of learning leaders who have impact on the quality of informal learning. Results from 82 completed surveys had been analysed, testing the correlations between the gamified learning usage and corporate learning leaders' minds, their competences and the organizational culture profiles of their companies. Three research propositions had been evaluated to determine if there are any relationships between these variables and none of them showed any statistically significant correlations. Consequently, this study showed no significant relationships between these attributes, so based on these factors no predictions can be made about the future of gamified learning and the real drivers of its implementation need to be found elsewhere.

An examination of the literature was undertaken to review studies that report about the concept of learning leaders' minds and their competences, the organizational cultural profile of the companies as well as gamification and gamified learning. A review of more than 30 papers describing relevant findings has identified a clear lack of investigations between gamified learning and the learning leader, as well as the organizational culture. This research is designed to explore whether the selected attributes play a critical role in determining the usage of gamified learning tools. Therefore, these study tests possible relationships between the practical implementation of gamified learning in the given company and its learning leader's mind, competences and organizational culture profile.

My research provides a source for academics and companies 
since it investigates connections between gamified learning and the learning leader as well as the organizational culture profile. Three research propositions have been supported by empirical data, which indicated that relationships between these variables cannot be proven, in other words, the trend of gamified learning and its longer-term implications cannot be answered categorically by these attributes.

This research has several limitations. The use of gamification in learning involves a number of aspects, including game elements, educational context, learning outcomes, learner profile and the gamified environment. Gamification is receiving attention, particularly for its potential to motivate learners. Accordingly, it is desirable to involve motivational impacts of gamification in educational contexts that can influence decisions of what categories of information to be included demonstrating the motivational effects of gamification on learners themselves. Not only are individuals motivated in multiple ways, but also their motivation varies according to the situation or context of the task.

Furthermore, the research sample could be more extensive in order to get more generalized results. At present, the population that could be surveyed is rather small and had been investigated in high quality, thanks to the carefully selected sample. The emergence of the cLo role shall result in extension of the current study, and involve more cLos in the surveying part of subsequent research. As further research directions, similar studies could be conducted on a larger sample of companies to be able to make valid conclusions regarding possible differences among companies of different size, region and industry. It might be worthwhile to investigate the corporate learning strategies of those industries that have specific status from the perspective of employee education (i.e. the healthcare industry where the content is driven by subject matter experts, there are continuous regulatory requirement updates and the majority of learning can be a compliance activity). An important field of further studies might be also the analysis of learner populations. It is recommended that a voice be given to the learning program's participants, their content consumption habits and learning patterns be examined in more detail, and ensure more fact-based targeting of the gamified learning program.

The literature dealing with impacts of learning leaders in corporate learning environment is still rare to find and the empirical studies of the link between learning leaders' key characteristics and implementation of gamified learning are even more challenging to find. 
Therefore, this study is a good starting point for future research about how learning leaders influence the gamified learning tools' longevity. Results of the research should also be used as a base for development of case studies that investigate how in particular, successful companies use different tools of the гст domain and what are the key influencers. These research findings can encourage companies to examine in more detail their current learning tool practices, and motivate them to introduce new approaches that can be used to apply gamified learning in a tailor-made way, and validate its impact.

\section{References}

Arneson, J., W. J. Rothwell, and J. Naughton, J. 2013. 'Training and Development Competencies Redefined to Create Competitive Advantage' https://www.td.org/Publications/Magazines/TD/TD-Archive/2013 /01/Training-and-Development-Competencies-Redefined

Arnold, B. J. 2014. 'Gamification in Education.' Paper presented at the American Society of Business and Behavioral Sciences Conference, Las Vegas, NV, 20-3 February

Baldwin, T. T., and C. C. Danielson. 2000. 'Building a Learning Strategy at the Top: Interviews with Ten of America's clos' Business Horizons 43 (6): 5-14.

Burke, B. 2012. 'Gamification 2020: What Is the Future of Gamification?' https://www.gartner.com/doc/2226015?refval=\&pcp=mpe\#dv_1_the future

Cameron, K. S., and D. R. Ettington. 1988. The Conceptual Foundations of Organizational Culture. In Higher Education: Handbook of Theory and Research, edited by J. Smart, 356-96. New York, NY: Agathon

Carr, N. 2010. The Shallows: What the Internet Is Doing to Our Brains. New York, NY: Norton.

Chatman, J. 1991. 'Matching People and Organizations: Selection and Socialization in Public Accounting Firms.' Administrative Science Quarterly 36 (3): 459-84.

Dale, S. 2014. 'Gamification: Making Work Fun, Or Making Fun of Work?' Business Information Review 31 (2): 82-90.

Deterding, S. 2012. 'Gamification: Designing for Motivation.' Interactions 19 (4): 14-7.

Deterding, S., D. Dixon, R. Khaled, and L. Nacke. 2011. 'From Game Design Elements to Gamefulness: Defining "Gamification."' in Proceedings of the 15th International Academic MindTrek Conference: Envisioning Future Media Environments, 9-15. New York, NY: ACM.

Elkeles, T., and J. Phillips. 2007. The Chief Learning Officer. Amsterdam: Elsevier.

Farr, J. S. 2014. 'Sharp Minds' The Eighteenth Century: Theory and Interpretation 55 (1): 1-17. 
Floyd, S. W., and P. J. Lane. 2000. 'Strategizing Throughout the Organization.' The Academy of Management Review 25 (1): 154-77.

Gale, S. F. 2015. 'clos: Agents of Change.' http://www.clomedia.com/2015 /02/23/clos-agents-of-change/

- 2007. 'The Synthesizing Mind: Making Sense of the Deluge of Information.' In Globalization and Education, edited by M. S. Sorondo, E. Malinvaud, and P. Léna, 3-18. Berlin: De Gruyter.

Gardner, H. 2008. Five Minds for the Future. Boston, MA: Harvard Business Review Press.

Gardner, H., M. Csikszentmihalyi, and W. Damon. 2001. Good Work: When Excellence and Ethics Meet. New York: Basic Books.

Garris, R., R. Ahlers, and J. Driskell. 2002. 'Games, Motivation and Learning: A Research and Practice Model.' Simulation \& Gaming 33 (4): 441-67.

Gratton, L. 2004. Aligning Corporate Learning with Business Strategy. Kingwood, Tx: The Concours Group.

Huizinga, J. 1955. Homo Ludens: A Study of the Play-Element in Culture. Boston, MA: Beacon.

Enz, C. A. 1988. 'The Role of Value Congruity in Intraorganizational Power.' Administrative Science Quarterly 33 (5): 284-304.

James, C., K. Davis, A. Flores, J. M. Francis, L. Y. Pettingill, M. Rundler and H. Gardner. 2010. 'Young People, Ethics, and the New Digital Media.' Contemporary Readings in Law and Social Justice 2 (2): 21584.

L'Allier, J. J. 2005. 'The cuo's Role: Preparing for Future Challenges.' http://www.clomedia.com/articles/the_clo_s_role_preparing_for _future_challenges

Landers, R. N. 2014. 'Developing a Theory of Gamified Learning: Linking Serious Games and Gamification of Learning.' Simulation \& Gaming 45 (6): 752-68.

Li, W., T. Grossman, and G. Fitzmaurice. 2012. 'gamicaD: A Gamified Tutorial System for First Time autocad Users.' Presented at the 25th Annual Асм Symposium on User Interface Software and Technology, Cambridge, MA, 7-10 October.

Likert, R. 1932. A Technique for the Measurement of Attitudes. New York: McGraw-Hill.

Kapp, K. M. 2012. The Gamification of Learning and Instruction: GameBased Methods and Strategies for Training and Education. Hoboken, NY: Wiley.

Meister, J. 2015. 'Future of Work: Using Gamification for Human Resources.' http://www.forbes.com/sites/jeannemeister/2015/03/30 /future-of-work-using-gamification-for-human-resources/

Nicholson, S. 2012. 'A User-Centered Theoretical Framework for Meaningful Gamification.' Paper presented at the Games+Learning+Society 8.o, Madison, wI, 13-15 June. 
O’Reilly, C. A., J. Chatman, and D. F. Caldwell 1991. 'People and Organizational Culture: A Profile Comparison Approach to Assessing Person-Organization Fit.' Academy of Management Journal 34 (3): 487-516.

O’Reilly, C. A., and J. Chatman. 1996. 'Culture as Social Control: Corporations, Cults, and Commitment.' Research in Organizational Behavior 18 (2): 157-200.

Petkovics, I., P. Tumbas, P. Matković, and Z. Baracskai 2014. 'Cloud Computing Support to University Business Processes in External Collaboration.' Acta Polytechnica Hungarica 11 (3): 181-200.

Polányi, M. 1962. Personal Knowledge: Towards a Post-Critical Philosophy. Chicago, IL: University of Chicago Press.

Rauch, M. 2013. 'Best Practices for Using Enterprise Gamification to Engage Employees and Customers.' In Human-Computer Interaction: Applications and Services, edited by M. Kurosu, 276-283. Berlin: Springer.

Rieber, L. P. 1996. ‘Seriously Considering Play: Designing Interactive Learning Environments Based on the Blending of Microworlds, Simulations, and Games.' Educational Technology Research and Development 44 (2): 43-58.

Schein, E. H. 1996. 'Culture: The Missing Concept in Organizational Studies.' Administrative Science Quarterly 41 (2): 229-40.

- 2010. Organizational Culture and Leadership. San Francisco: Jossey-Bass.

Scipione, P. A. 1992. Practical Marketing Research. Dubuque, IA: Kendall Hunt.

Shapkova, A., V. Dorfler, and J. MacBryde. 2017. 'Changing the Game: A Case for Gamifying Knowledge Management.' World Journal of Science, Technology and Sustainable Development 14 (2-3): 143-54.

Shukla-Pandey, S. 2014. 'Unmask Your Employer Brand.' HRM, $26 \mathrm{Au-}$ gust. http://issuu.com/keymedia/docs/hrm_14.09_main_mag_e-zine

Smith, A. 2008. 'Cultivating the Ethical Mind with Games and Simulations.' Paper presented at the World Conference on Educational Multimedia, Hypermedia and Telecommunications (EDMEDIA) 2008, Vienna, 3-4 June.

Sugrue, B., and D. Lynch. 2006. 'Profiling a New Breed of Learning Executive.' Training + Development 60:51-8.

Szeghegyi, Á., V. Szoboszlai, and J. Velencei. 2014. 'Informal PostExperiential Learning.' Acta Polytechnica Hungarica 11 (4): 241-52.

Szoboszlai, V., J. Velencei, and Z. Baracskai. 2014. 'Post-Experiential Education: From Knowledge to “Knowing."' Acta Polytechnica Hungarica 11 (10): 235-47.

Torgerson, W. S. 1967. Theory and Methods of Scaling. New York: Wiley.

Uskov, A., and B. Sekar. 2014. 'Serious Games, Gamification and Game Engines to Support Framework Activities in Engineering: Case

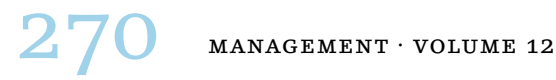


Studies, Analysis, Classifications and Outcomes.' Paper presented at the IEE International Conference on Electro/Information Technology, Milwaukee, wi, 5-7 June.

Vandenberghe, C. 1999. 'Organizational Culture, Person-Culture Fit, and Turnover: A Replication in the Health Care Industry.' Journal of Organizational Behavior 20:175-84.

Van Eck, R. N. 2006. 'Digital Game-Based Learning: It's Not Just the Digital Natives Who Are Restless.' Educause Review 41 (2): 16.

Van Eck, R. N. 2007. 'Six Ideas in Search of a Discipline.' In The Design and Use of Simulation Computer Games in Education, edited by B. E. Shelton and D. Wiley, 31-6o. Rotterdam: Sense.

Woods, R. H. 1989. 'More Alike Than Different: The Culture of the Restaurant Industry.' Cornell Hotel and Restaurant Administration Quarterly 30 (2): 82-98.

Wood, R., and A. Bandura. 1989. 'Social Cognitive Theory of Organizational Management.' Academy of Management Review 14 (3): 361-84.

Zielinski, D. 2015. 'The Gamification of Recruitment.' http://www.shrm .org/publications/hrmagazine/editorialcontent/2015/1115/pages/ 1115-gamification-recruitment.aspx

This paper is published under the terms of the Attribution-

NonCommercial-NoDerivatives 4.o International (CC BY-NC-ND 4.0)

License (http://creativecommons.org/licenses/by-nc-nd/4.o/). 